\title{
Sprouting Wings in the Hyper-Colonial: High-Octane Desire and Youth-Targeted Market Predation
}

\section{Mark B. Borg, Jr.}

Community Consulting Group, New York, USA.

Email: oedtrex@aol.com

Received July $14^{\text {th }}, 2010$; revised July $31^{\text {st }}, 2010$; accepted August $3^{\text {rd }}, 2010$.

\begin{abstract}
In this article, the author utilizes a novel action research approach to developing an interpretation of a colonial discourse that reproduces an otherness that is consistent with traditional views of history and ideology. Through this unique educational-for both author and client-approach, further analysis reveals a colonial discourse that has become unhinged from its historical roots and taken flight into supermolecular space where its origins and impact have been thoroughly dissociated from its cultural impact. When our identities are thoroughly absorbed into and taken over by consumer products, we enter a corporately induced, mass-media augmented hyper-colonial in which our minds, bodies, and senses of self become defined by those products. A primary research question is: how can we intervene in colonialism when the colonized is an inferior/lacking version of our own self? The ways in which this hyper-colonial state captures and makes use of desire and is then marked-marketed-by/through a society-level drive is explored throughout this article. The author "takes a walk"-that is, he uses a week-long organizational consultation that was conducted for a marketing research organization to analyze the ways that the dynamics of a hyper-colonialized consumer culture were at play in the consultee's marketing strategies that target American youth.
\end{abstract}

Keywords: Hyper-Colonial, Consultation, Action Research Education, Consumer Products, High-Octane, Marketing

\section{Introduction: Under the Influence of...}

In the first half of their "Capitalism and Schizophrenia" series, Anti-Oedipus, Gilles Deleuze and Felix Guattari claim that "A schizophrenic out for a walk is a better model than a neurotic lying on the analyst's couch" [1]. While that might seem like a wild and untenable position, let me suggest that what they mean by "schizophrenic" has everything to do with the emotional condition wherein one is as totally and absolutely accessible to the data-via sensory impression, stimulation and even over-stimulation - that our world has to offer (sight, sound, smell, taste, touch, not to mention emotion itself). Being "schizophrenic" is being in a state where everything (including, most especially) we ourselves become "desiring machines" [1] — where we can make connections and more connections between ourselves and the world around us, connections that, from the shutdown, anxious and/or depressed "neurotic" state we are safely defended against; and, therefore, we miss out on much of our lives. In this paper, I am suggesting that the "schizophrenic" position conceptualized by Deleuze and Guattari, an opportunity for a new variety of educational experience - using this as a model for Action Researchawaits.

And, so...

In this article, the author - in the role of organizational consultant - undertakes an analysis of colonial dynamics in global times, and does so via the process of taking a walk from as Delezian/Guattarian a position as is (humanly/machinically?) possible. I present an analysis of the camouflaged colonial discourse that directly and overtly reproduces otherness in ways which are consistent with traditional views of its historical and ideological underpinnings and effects, and then propose that such analysis sets the stage for conceptualizing a colonial discourse that has become unhinged from its historical roots and taken flight into supermolecular space, where its origins have been thoroughly dissociated from its cultural and contemporary effects and the dynamics that sustain it. 
In this process, we can see that "although the physical instruments of brutality associated with imperialism are no longer in direct use, the colonial instruments live on in contemporary advertising and related discourses" [2]. When our identities are thoroughly absorbed into and taken over by consumer products, we enter a corporately induced, mass media-augmented hyper-colonial in which our mind, body, and sense of self become defined by those products. Colonialism is replaced by hyper-colonialism, which then becomes a vanishing mediator; like capitalism itself, the colonial influences are disassembled from their colonizing - and ubiquitous - influence and force. The (dis-)associated dynamics, especially as related to consumption practices/rituals, then become part and parcel of - and unconsciously accepted as - the social-economic-political context/climate within which we operate (under the influence of...).

Children and adolescents are particularly vulnerable to the influence of these mediators, as children are "essentially invisible in theories of consumer society and culture" [3]. Children (as well as the parents, adults, and institutions that engage with them), especially during time periods of development when social insecurity is high, then represent targets for colonial marketing strategies that have been mainly ignored [4]. Such insecurities become associated with an overall sense of - a lack in - self, and marketing strategies target this insecurity as part of a package deal where insecurity equals inferior (and lacking), which in turn requires intervention (augmentation) and overcompensation for this lack that has been induced by the dynamics of the consumption culture itself A primary research question is: how can we intervene in colonialism when the colonized is an inferior version of - and a lack at the core of - our own self? This begins to describe a process whereby the hyper-colonial apparatus captures and makes use of desire and is then marked - marketed - by/through a society-level drive to consume (more and more...).

\section{Road-Trippin' with the Root-Beer Man}

I recently completed a consultation in Southern California with Mr. D., the marketing director of a newly established marketing research organization. The goal of this consultation was to help him conceptualize, strategize, and organize his role in this new position. Since the company is still in the dream stage, he is currently gaining frontline experience by consulting to an already established research group. Every day you can find him in Los Angeles, San Diego, or Orange counties, driving a huge truck with numerous spigots on one side. His job is to pour beverages from those spigots, pass them out, and then - through some version of an interview-monitor/record the responses of the drinkers. I was thrilled to know that my consultation would take place in this monster vehicle while scouring the California coast in search of opinions on high-octane energy drinks. Despite the fact that the beverage being tested was Red Bull ("the drink that gives you wings"), Mr. D. has come to be known around Southern California as the "Root Beer Man" (as he drives around SoCal in a huge Thomas Kemper - itself a marketing research organization-rootbeer truck).

While I could explore the development of Urban Sensor, much of our weeklong conversation focused instead on the brief history and cultural location of high-energy drinks. Mr. D and I discussed the many ways that the combination of marketing strategies and popular culture serve as psychological and institutional responses to, and the exploitation of, youth in western societies. Through highly charged products such as Red Bull (and high-octane energy drinks in general), it is possible to show how corporate commodification is indoctrinating a younger generation into a globalized and colonized set of cultural rituals [5]. And these colonial processes, if they are implemented during a time where one's so-called self is at its height of suggestibility, will not only influence but also inhabit and become synonymous with one's very sense of self. If all goes well in the budding evolution toward the status of consumer, a new colonized self will serve as a stand-in for the one that was proven to be lacking/inferior in the marketing discourse itself. Consistent with this assertion, Alison Hearn suggested that

work on the self is purposeful and outer-directed; self-production is heavily narrated, marked by visual codes of the mainstream culture industry, and subject to the extraction of value... [and taken together this constitutes a kind of] self-branding, found across several different kinds of media, and illustrate the erosion of any meaningful distinction between notions of self and capitalist processes of production and consumption $[6, \mathrm{p}$.].

The end result: a generation that is branded with the markings - and inhabited by the insatiable socio-dynamics of infinite and insatiable drive - of a neoliberal and atomized consumer society.

\section{Research Design}

The underlying ideological frameworks that underlie colonialism and hyper-colonialism and their effects are often invisible to those who are subsumed in/by them and are difficult for consumers to articulate. Therefore, I employ a methodology that explores aspects of these effects, and the enactment of the dynamics that represent these effects, through a socio-cultural reading [7] of how one in marketing-Mr. D. (AKA, the Root Beer Man)conceptualizes his role and the sense that he (and he and I together) makes of informant narratives about repre- 
sentations of product use-value, superiority, and overcompensation implied/offered through the vehicle of advertising. My analysis specifically addresses colonial dynamics as they were imposed upon young people through the quite leading questions that were developed by the marketing research department of his company and delivered by Mr. D. The informants, in general, were not actually asked questions regarding preference of one beverage compared with another (as is traditional in market research); instead, they were asked to describe in detail how Red Bull worked for them, what it did/does for them-questions that would encourage them to describe what would essentially be their relationship to/with Red Bull. This article, therefore, primarily focuses on Mr. D's telling the "story" of Red Bull, his experience as "marketing researcher," and how he and his organization articulate - and rationalize - their primary task. However, the narrative ultimately comes together through an analysis of the dynamics associated with how it was that Mr. D engages with the consumers.

In actual practice, I undertook a participant-observation stance in what was contracted as an action research consultation [8], and joined Mr. D in pouring out small cupfuls of Red Bull and observing, and recording, both his manner and style of inquiry as well as the responses of the informants. Mr. D's primary research method in his role for Urban Sensor was narrative research-and my own research of his role and process was in parallel with his methodology. The aim of the research was to understand how individual informants consume not only the beverage itself, but the whole image and representation of the product as it has been delivered to the public by not only Mr. D but through a panoply of marketing strategies that have resulted in some-many-of the informants in fact describing their relationship with the product. Similar to Money, "the emphasis [was] formerly placed upon individuals and how they 'make sense' of [this product] and, in turn, how they narrate this to others" [9]. This research relates to the idea of "narrative functions" [10] and the idea that the stories concerning consumer culture - objects/products - can provide access to ideas about lifestyles, cultures, and everyday life.

Of the well over 300 informants, 56 (31 females, 25 males) individuals between the ages of 18 and 25 (the product's "target segment") agreed to take the semistructured interview that took place in a variety of Southern California locations-primarily, Newport Beach, Laguna Beach, and San Diego. These are affluent areas, and the informants who were formally interviewed were nearly all Caucasian, and from upper SES households. Semi-structured interviews were selected as the principal method of data collection. This article primarily focuses on the narrative that was delineated through my conversation with Mr. D (qua marketing imperialist) and the ways in which a colonial discourse was made manifest in his articulation of Red Bull as product par excellence (which became increasingly mythologized and romanticized as the week wore on), the enactment of his role, as well as in his actual engagement with the "target segment" for the product he was researching himself.

\section{High-Octane Drinks for the $\mathrm{Y}$ and $\mathrm{Z2}$ Generations}

Mr. D stated, "The US has increasingly become a society in constant need of a pick-me-up. America's overexposure to caffeine is marked by the large number of Starbucks and Starbuck clones found on what seems to be every other street corner." These pick-me-ups may represent a version of our growing palliative care system - that is, our increasingly complex methods aimed at reducing pain and distracting ourselves from sources of everyday anxiety that can, at times, be (or seem to be) unbearable [11]. "Feeling better" itself has become the new "civilizing mission" [2] toward controlling global resources and transforming the colonized into full-bred consumers. The effectiveness of this strategy requires an ideological framing to support the colonizer's attempts at subjugating the colonized [12,13].

Many 30- to 50-year-olds (late boomers and maturing generation $\mathrm{X}$-ers) are well-acquainted with the withdrawal headaches that accompany 24-hour periods without coffee or other caffeinated beverages. Mr. D and I wondered together what fate may await members of generations Y (ages 12-19) and Z2 (ages 8-11) who are the prime targets of energy drinks, which might be the adolescent equivalent of the adult-versioned double hit of espresso mixed with mega-doses of sugar and milk. Of course, when answering this question, we have to consider the possibility that it may not be the drink that is so addictive, but the underlying message that success-or maybe just daily survival-demands a pick-me-up! "Feeling better" and being "picked up" are no longer simply emotional states in this process. Instead, they are mandates - they are demands for how one should feel/be, and certainly how one should respond when asked [11, 14]. In this sense, these mandates have ideological implications.

"Ideology," as Bonsu suggests, "is a system of thought that maintains particular forms of power relations, which are often invisible to those who are actively involved in its dispensation...Colonial ideologies related to images of conquest and subjugation found residence in media and other discourses" [2]. The core of these discourses renders colonial subjects into a subhuman status; and, in the case of hyper-colonial subjugation, a part of the self must first be split off so that it can be the subhuman 
other to be subordinated by what will eventually become the consumerized self. An ideology of palliative care- feeling better-entails a process of increasing dissociation from the parts of the self that do not measure up to the demands of this mandate.

Mr. D stated that, "Because of its $56 \%$ market share, Red Bull is the product most often mentioned by gen $\mathrm{Y}$ and $\mathrm{Z} 2$ kids when they discuss the highlights and nuances of their relationship with high-octane energy drinks." Sixteen-year old Jenny described how her boring and pathetic life (her pre-colonized sense of self perhaps) was transformed when she started "using Red Bull." Twenty-one-year-old Mike jokingly told us that it gave them "wings," which led to the end of his previous practice of "Doing the Dew" (the marketing slogan for the caffeinated soft-drink Mountain Dew).

One might assume that such descriptions allude to getting high or flying above the woes of mundane existence, and this perspective is encouraged by website advertisements showing cows hang gliding after drinking a can of Red Bull. This particular advertisement is interactive - by moving your mouse back and forth, you can make a cow grow wings, take flight, and jump over the moon. In the same manner as cigarette advertising, this raises questions about the ethics of such sophisticated marketing efforts being aimed at inducing adolescents and pre-adolescents to consume a product that contains adult doses of caffeine. Of course, the power of discourse itself lies in its ability to constrain people from seeing the ideological work it performs $[13,15]$. Fifteen-year-old Steven told the Root Beer Man, "I only use it when I need to, like, after being up all night or when I want to hang out late with my friends. You know, not like every day." The use-value of the product, in these examples, operates in a constraining manner, which masks our ability to recognize our support for the rhetoric of superiority - the fact that we can now feel superior to our "boring" and "pathetic" non-octane pre-selves.

Looking at the growing sales figures for "high-octane energy" drinks, it looks as though they are here for the long run. Red Bull achieved record sales in 2008, thanks to a strong performance in fast-growing markets in the Far East and Canada. Red Bull, which is not listed on the stock exchange, said it sold 4.02 billion cans of its energy drink in 2008, up $13.2 \%$. By value, sales rose $7.9 \%$ to 4.3 billion dollars. Sales in Europe grew 12\%, with the Far East up 79\%, Canada 50\%, the Middle East 31\%, and South America 26\%. As mentioned above, Red Bull is the category leader with a $56 \%$ market share.

Energy drinks seem to be favored by today's pop stars, with actor/rapper Ice-T recently working with Multimedia Distributing to create a product called Liquid Ice, and Nelly launching a brand called Pimp Juice. Already, these upper-SES, gated-community, Caucasian (i.e., boring) selves are being linked up with the Gangsta Rap culture. Guaranteed, gen Ys and Z2s will never be rightfully accused of lethargy as the energy drink phenomenon joins Viagra on the list of life's little necessities. Why sit around playing video games when you can jump up and down and act — or feel — as though you're in one!

\section{Mythological Origins of the Globalized Product}

Mr. D, himself a Californian, said, "Legend has it that Robitussin cough syrup, because it was foretold to have enough alcohol to create a short but sharp high, was a beverage choice among Southern California teenagers at one point. Red Bull tastes considerably better than cough syrup, but the end result is the same: a legal sense of euphoria." However, according to the Root Beer Man, the street wisdom is that the Red Bull currently being sold in the US is an inferior product whose success comes from exceptionally clever marketing techniques - packaging, distribution, and spin.

Spin begins to create and sustain a new territory, where selves can be spilt (dissociated), where alien power relations begin to infiltrate the mind and wage an internal battle where inferior self is transformed into other, and a superior (via overcompensation) consumerized self takes over. At this point, we can now engage the colonial discourse at the core of the Red Bull story. Bonsu, regarding the ways that traditional (i.e., overt and direct colonial) tactics have been replaced by insidious dynamics that have gone sub rosa, writes:

The presumed demise of colonialism suggests an attendant decline in the use of colonialist equipment that sustained the dynamics of the era, implying that colonial ideologies and the rhetoric of difference that defined categories of otherness toward subjugation may have waned. The seeming demise also funds a latent process that entrenches colonialist ideologies in contemporary media audiences. It allows the dominant globalization discourse to engage in acts of imperial power that paint specific portraits of colonialism-informed inferior others. In doing so, globalization supports the mining of colonial tropes and the invention of new forms of representation that enforce colonial-era power relations [2].

Spin, advertising, and marketing strategies in general, then, become the new forms of representation that enforce/reenact colonial-era power relations.

Red Bull's spin, as described by Mr. D, begins with its "rags-to-riches" origins. He stated:

Red Bull was originally created in Thailand - a land known for water buffalo and not beef cattle. It has been a favorite of long-distance truckers, who guzzle it while traveling thousands of miles per week with very few rest 
stops. In Thailand, everyone from factory workers to salaried office employees recognize the distinctive Red Bull bottle as a reliable friend helping them make it through the long work days that are the norm in Southeast Asia. This is obviously a very different kind of use-value from that employed by U.S. teenagers. Then again, the colonial dynamics do not seem to go hyperuntil the product/object penetrates a cultural space ripe for augmenting (or substituting) self with (for) consumer product (identification). In Thailand, a bottle of Red Bull (or Krating Daeng in the Thai language) currently costs 10 baht - about 23 cents U.S.; in the U.S.: \$2.50/can.

Mr. D continued his narration to describe how Austrian Dietrich Mateschitz signed a licensing agreement with Red Bull's parent company, TC Pharmaceuticals, in 1984. He added carbonation and adjusted the recipe to make it taste more medicinal, then marketed the product as a hot new club drink to be taken by anyone feeling a bit low on energy but determined to "party "till dawn." Red Bull wings were aimed at young men for whom individualistic, alternative lifestyles were the ideal. Mateschitz waited until 1997 to enter the U.S. market; Red Bull is now part of the multi-billion energy drink segment of America's $\$ 60$ billion soft drink market. ts success confirms the adage that the company that organizes the best marketing campaign will win, regardless of product quality - an adage that Urban Sensor aspires to emulate. But the way that certain winners spin their products (and representations of such products) into cultural symbols raises the question of how such products contribute to and/or change the cultural climates in which they are embedded.

\section{High-Octane ID}

All objects of human construction can be analyzed in terms of what they say about the individual, group, community, or corporate entity that created them. From this perspective, they send messages influenced by personal opinions, preferences, desires, prohibitions, and fears. Their originators put a great deal of effort into reading us [16,17], and, consciously or otherwise, we cannot help but read and acknowledge the messages they want us to receive. This, however, first requires a process of reforming the consumer mind to adopt the colonizer's worldview [18]. In classic Foucauldian fashion, the colonized implicitly accept a subservient role without conscious effort and defend the colonizer to rule over (or in) them [19]. Of course, we read the messages (especially transmitted through brand symbols and slogans) sent from the colonizer's from the perspectives of our own individual histories, character structures, and psychopathologies: if I'm paranoid, the messages confirm that I'm a target; if I'm narcissistic, they confirm my uniqueness; if I'm psychotic, perhaps from the rocks, the insects, the government, or the aliens [20]. This symbolic bombardment itself constitutes a pervasive and chronic form of violence [21].

Those who Mr. D interviewed-from a relational perspective-assume that they can plug into a high-octane identification without concern for what effect this overcompensation for their internal smallness will have on the actual world. In the induced need for overcompensation and power, high-octane identification is another assemblage to be plugged into to shore up a fragile sense of security in the delusional belief that security = satisfaction. That (fleeting sense of) satisfaction dislodges dissociated desires, though in so doing only postpones its actual fulfillment, and in a deep sense of deprivation, one might be convinced that he/she needs this "flight" just to survive the turmoil of adolescence (the primary target segment for Red Bull). This then sustains a sense of apathy as to how consumptive behavior becomes synonymous with one's sense of "I" (who have) against the backdrop of fantasied "other" (who does not have, envies me, my size, my importance, etc.). This sets up then a kind of society-level inversion - a Folie à deux where the other (qua fantasy societal-screen upon which I project my own insecure/lacking sense of self) is the representative of the very lack that I feel in myself.

To what degree is this same process being played out in the larger social sphere? To what degree is Red Bull speaking to members of the Y, Z2, or any other oddly labeled generation? Similar processes may be going on in the minds of adolescents who talk about how they use Red Bull- “Only when I need it!" The term high octane is both compelling and highly suspect in terms of potential overcompensation for a void of infinite lack that is created and sustained by the marketing industry.

\section{Entering the Hyper-Colonial}

The combination of mass marketing strategies and media targeting makes it seem as though the sprouting of wings will be brought to us and our children in vivid Technicolor on a flat-screen, high-resolution LCD video unit. Using a mix of fantasy and desire, corporate functionaries have created a $21^{\text {st }}$-century cultural perspective based on corporate ideology and free-market values-what Steinberg and Kincheloe have labeled the new "cultural curriculum." They believe that The organizations that create this cultural curriculum are not educational agencies but rather commercial concerns that operate not for the social good but for individual gain ... Patterns of consumption shaped by corporate advertising empower commercial institutions as the teachers of the new millennium ... we must intervene in this cozy relationship between popular culture and pedagogy that shapes our 
identities, we must exercise our personal and collective power to transform the variety of ways corporate power-gained via access to media-oppresses and dominates us [22].

When our identities are thoroughly absorbed into and taken over by consumer products, we enter a corporately induced, mass media-augmented, hyper-colonial in which our minds, bodies, and senses of self become defined by those products (product labels and slogans become inscriptions on our psyche). Ngugi states that Colonialism...relates to the use of discourse to fashion a targeted image of a particular culture or group of people. It serves to extend the political power of the dominant culture over the subjugated other. The priority of colonialism and its variants is to facilitate cultural acquisition via conceptual assimilation [23].

And, whereas great powers were once able to militarily and economically occupy conquered territories for exploitation and gain [24], national and international corporations create and sustain a sense of culture and thereby now occupy realms of consciousness [25,26]. As colonizers, these organizations benefit from occupying the human psyche [27]. Using their power to enter the private lives of children and adolescents, the corporate producers of high-octane symbols destabilize the identities of youth [28]. High-octane drinks exemplify the processes by which marketers wage constant war over whose product will reach the level (label) of stability that comes from being identified with excellence through consumption. And this sets the cornerstone for the intergenerational transmission of hyper-colonization. After all, cultural artifacts have always assisted in the processes of creating/fabricating ourselves and our social affiliations (including product loyalties); the contemporary process entails the corporate colonization of both cultural values and personal/group consciousness.

We are currently dealing with a system of representational politics in which commerce serves us a form of cultural production that elevates aesthetics to their most ubiquitous organizing principle [29]. According to French cultural theorists Gilles Deleuze and Felix Guattari, the media deterritorializes our identities to allow corporations (or products) to reterritorialize them [30]. Culture and commodity become indistinguishable in this matrix, and social identities are shaped almost exclusively within a consumerist ideology of deterritorialization (sprouting wings) and reterritorialization (clipping wings): in need of more wings. In Henry Giroux's words,

Commercial culture, coupled with popular culture, has become the new transnational force used by global capitalism to both capture and open up markets, as well as to redefine the very nature of identity, needs, desire, and democracy itself. Stripped of its political context, de- mocracy, under the onslaught of global capitalism, is transformed into market relations, and citizenship is reduced to the obligations of consumerism [31].

We live surrounded by the commercial equivalent of carpet bombing, attacked with an endless array of consumptive images hyper-colonized by globalized forces that now represent the contemporary evolution of the symbolic order we are both captured by and embedded within. And, to exist outside or beyond it is to cease to exist at all. The guiding message of this symbolic order was the focus of a comment made by former Senator Bill Bradley (a prominent liberal spokesperson) that the United States is "in danger of losing a generation of young people to a self-indulgent, self-destructive lifestyle" [32]. However, Bradley appears to demonize the youth who are caught up in the lifestyle and fails to implicate adults and the corporate colonizers whose oppressive tactics usurp the false structure of a mythologized democratic system that now serves as but a stand-in for the rapacious hyper-colonial system which incessantly replaces it.

\section{Hey Butterfly, Pop a Red Bull, Get in Your SUV, and Sprout Wings-The Nets Await}

In the hyper-colonial the things (i.e., commodities) are used in a manner that says something - much/ everything - about the user. The Red Bull consumer might say (and believe), "I am larger than life"; "I feel that I have risen above and beyond my corporeal reality." As I suggested earlier, objects may find use value as a psychological defense, compensating for a chronic sense of smallness or meaninglessness within an otherwise vertiginous social or symbolic order [33]. According to Marx's conceptual framework, commodities appear to consumers as though they are endowed with special powers - that is, they are fetishized [34]. Zizek asks if this is what Marx was referring to in the following excerpt from his famous fiction about commodities communicating with each other:

If commodities could speak, they would say this: our use -value may interest men, but it does not belong to us as objects. What belongs to us as objects, however, is our value. Our own intercourse as commodities proves it. We relate to each other merely as exchange values [35].

Of course, some objects not only "symbolize" power but also put the acquirers into positions of exercising power. The product's (fetishized) insignias/messages are external (not part of one's nature): I internalize-not merely ingest - Red Bull to assert power, my place in the world, and/or my need to fit in. Red Bull then introduces a gap between what I (as the user) am and the function I exercise sustaining an internal project involving Mani- 
chaean essentializations where devalued pre-self is replaced by self-in-flight (i.e., complying with the mandate: feeling better now).

Since there's really nothing there but cognitive artifact and social construction, the gap between what I am and the symbolic mandate that confers "authority" (my entitled position in consumer society) to me is fraught with impotence - in other words, I may fly, but there won't be anything to catch me if (or when) I fall. Are we already so unhinged from our senses of self and of self-and-other that flying has become a metaphor for our current state? By flying, I don't mean in an exhilarating sense, but agoraphobically floating in a social atmosphere that makes us feel the lack of grounding of our individual and mutual experiences-dreading the immanent tank, the fall into death (drive). As Zizek notes:

The paradox of the Freudian "death drive" is...that it is Freud's name for the very opposite, for the way immortality appears within psychoanalysis, for an uncanny excess of life, for an "undead" urge which persists beyond the (biological) cycle of life and death, of generation and corruption ... human life is never "just life": humans are not simply alive, they are possessed by a strange drive to enjoy life in excess, passionately attached to a surplus which sticks out and derails the ordinary run of things [36].

In our sense of excess, of universal surplus, we can become detached-have taken flight, finding ourselves sticking out and derailed (or unhinged), and taking a nose dive into oblivion - from the use value of any and all exchanges (emotional, social, and communal). Marx acknowledges the dual position of material production as "the (re)production of the social relations within which it occurs" [34]. And, therefore, we are catapulted into undead - think zombie, vampire-excess/surplus (of desire/enjoyment) that is the death drive.

All drives, then, share with desire the property of never achieving their aim [37]. The drive always circles around its object but never achieves the satisfaction of reaching it. The purpose of drive is simply to maintain its own repetitive compulsive movement, just as the purpose of desire is to desire. This then sets up an imbecilic cycle, where we can become attached to market forces through some bizarre social $X$-(or Y or Z2) factor that works like an algebraic remainder that parasitically becomes a core part of our own individual, and isolated, self-identity - not realizing how the colonial imagination has been smuggled into contemporary discourse, and how we are under its influence. This dynamic process then enacts a living form of internalized and acted-out conjunctive synthesis where we can live out our repetitive desire-become-drive ad infinitum, where we connect and connect and connect to repetitive need/lack/need/ lack
(...), and are infinitely available (and easy) targets for the hyper-colonial forces that undergird our every step.

And why are we labeling our respective generations with algebraic Xs and Ys, and Z2s? Does this signify what we are currently reproducing (the death drive) in terms of social relations - especially in terms of market segments? We target the Ys and Z2s for Red Bull marketing pitches and X-ers for SUVs and Caribbean holidays. These symbols convey how easily we have been transfigured into algebraic groups of prey for advertising and marketing predation. Algebra is all about taking unknowns and giving them numerical value - the first step toward capturing exponentials in geometry and calculus. The elements contained in the capturing process-individuals, groups, corporations, governments, etc.- - begin to resonate and destabilize the separation between the elements themselves. This is a perfect scenario for hyper-colonial fascism: an externally imposed and internally regulated set of established standards that authoritatively dominate the social unconscious.

The techniques applied to both adults and youth are so similar that they bring to mind Freud's "narcissism of minimal differences" [38]. This dynamic has been used to explain in-group/out-group discrimination - that is, I need a "you" on which to project all the unwanted parts of "me." The "narcissism of small differences" formula goes something like this: a) although two groups may seem alike, they have minor differences; b) rituals are developed to maintain these minor differences and to maintain a psychological barrier between the opposing groups - a barrier that absorbs the flow of aggression and (in times of peace) stops members of the two groups from killing each other $[39,40]$. However, this is particularly problematic as the minimal difference being sustained is between a pre- and post-hyper-colonized self (self becomes other and dissociated).

In like manner, corporate impersonalization sustains oppressive marketing techniques by desubjectifying their targeted populations. The predation becomes displaced: it is not my children, my family, or me who is being oppressed and/or hyper-colonized, it is some abstract other-a rival, an enemy, ultimately an inferior version of myself-who probably deserves it [41]! And the narratives presented by Mr. D and his cadre of informants were, overall, consistent with colonial ideologies [42] that seek to camouflage the instituted order of differences and hierarchies. The implication is that without these differences-without containers for projecting the unwanted and intolerable aspects of ourselves - we would become fragmented, lose all sense of our unique identities, and forsake our special status in the socio-symbolic order. This essential difference arises when we subtract the false and simulated differences from the "pure" dif- 
ferences between individuals or groups and the backgrounds of popular culture implemented by corporations and sustained by hyper-colonialism. The necessity of sustaining this essential difference works quite well for establishing our status as targets for vast, impersonal market forces, wherein society projects its darkest aspects onto individual consumers or targeted groups [43].

It may be too early to tell what kinds of effects-actual and placebo-will come to be associated with high-octane desire and the marketing slogans that promote it (e.g., "It gives you wings"). From a naively optimistic perspective, the high-octane obsession might stop a future generation or two from engaging in and experimenting with drug and alcohol abuse. But substituting high-octane desire for the drugs and experimental character styles used by previous generations may not be as innocent or innocuous as it first appears. Considering the synonymy of desire/drive and identity in our culture, the implications of a high-octane identity could be problematic for a generation needing a flimsy grandiosity to compensate for an unconscious angst over being perceived as corporate prey. This substitution/compensation process becomes especially dramatic if we consider how it simultaneously ushers us in and sustains our sense of being wholly consumed by the driven mandate to consume that penetrates into our individual and social psyche(s) straight from the nonverbal voice of the hyper-colonial.

\section{Conclusions: The Effects of Road Trippin' on Urban Sensor}

"Wait a minute," the Root Beer Man stated with alarm as we went over our case notes and headed toward the termination of our consultation, "We're just talking about the mundane topic of youth beverage drinks, right?" His (feigned) alarm suggested that perhaps what we were exploring together was really just mundane (i.e., "normal") life and how it has been chronically carnivalized to the point that our positions and identities within it begin to transgress familiar territories as they enter hyper-colonial space. But let's not let Mr. D's seemingly naïve question fool us.

Education through the analysis of "normal life," through being in that "schizophrenic" state (model) of being just "out for a walk' [1] had seemed to accomplish its goal.

One might notice while reading through this paper a significant paucity of analysis of any overt reference to signs and representations of product (i.e., Red Bull). And that is the point. We are at a point in the history of high-octane (desire/drive) products where we no longer need their multiform representations for them to have life inside of us. The messages that were once transmitted through such signs have taken flight and now exist in the cultural imagination (nobody needs to advertise the benefits of capitalism over, say, socialism, right?). A further analysis reveals how Mr. D's approach to his consultation project reveals/repeats the underlying hyper-colonial dynamics/discourse that we have been exploring in this article.

Let's think back for a moment on Mr. D's marketing strategy. He drives around SoCal in a Thomas Kemper root beer truck - in fact, he is known as the Root Beer Man. He wears a black tee-shirt, audacious surf jams, and flip-flops. Something is missing. He is researching Red Bull, but he (re-)presents nothing-no banners, no running video stream, and not even an actual can of the drink with its bright yellow bulls, in a backdrop of blue and silver, in near collision - to suggest that what will be spurting out of the spigots on his truck will, in fact, be Red Bull. His tactic goes further than the mere presentation of the blank screen technique where children can simply project their fantasies onto/into the product; Mr. $\mathrm{D}$ substitutes one fantasy (self) for a superior one. He seems to offer an inferior product (root beer), and then replaces that (lacking) product with a product that "gives you wings." Though he does not tell the recipients/informants that he has replaced the product (at least in terms of presentation), by the time most of them are engaged with it/him, they seem to know it, and therefore the responses obtained in the interviews (especially as they relate to the relationship that one has formed to/with Red Bull) reveal the cultural placement-at this point in time - of the product, leading to the discovery of just how extensive Red Bull's cult following is at this point in time. Red Bull, with 12 years of marketing/advertising in the U.S. under its belt, no longer needs any kind of launch pad to continue its flight (in the cultural imagination).

Regarding the discovery of what is to be the next universal surplus item, we might find in such discoveries that we are all capable (if not willing) of being unhinged from the use value of any and all exchanges. This is the process revealed in the final analysis of Mr. D's engagement with the consumer market. Those in market research can then register and quantify our reactions to the product du jure in order to provide insights for companies who want to build cult followings for new products (e.g., Diet Red Bull). This insight is used to help them help us (and our children, families, societies, etc.) fill in the void that exists in the people who seek connections with something/anything (i.e., their products). This filling-in allows us then to chronically dissociate the lack that underlies the universal-become particularizeditem/Thing (das Ding). The Thing_Das Ding — is the beyond of the signified - that which is unknowable in 
itself. It is beyond symbolization - a lost object that must be re-found. However, and this is the trick, it was never really there in the first place [44].

Once das Ding becomes the undead representative of our anthropomorphized object/other (in fantasy and through implicit communal consensus), it sustains the cycle of missing-the-mark (drive: imbecilic repetitive motion sustaining desire through its lack of fulfillment) and becomes the sliding foundation for marketing endocolonization. Paul Virilio and Sylvere Lotringer [45] coined the term endocolonization, a sociological/psychological process where individuals identify with oppressive forces and attempt to colonize their own groups or families with the belief systems of the oppressor group. Of the process of endocolonization, Krautwurst notes two aspects:

One macrosocial, wherein a war economy is carried over into peacetime, is restraining potential development in civil society. The other microsocial such as the human body is increasingly becoming a site of technology itself. Like all colonization, endocolonization is an emptying out, a deterritorialization, conducted in conjunction with a technoscientific reterritorialization which disrupts and fractalizes human and social totalities, which should remain whole [46].

Endocolonization is marked by the unconscious recognition that sources of security and protection are "emptied out," and therefore are also sources of oppression and terror ("disruption" and "fractalization"); this results in overlooked psychological trauma that can lead to strongly dissociated experiences in individuals $[47,48]$, families [49], and communities or cultures [50-52].

Mr. D's organization is not disputing what has become a core tenet in American life, which is to look outward (or into the fictive forward) rather than inward for fulfillment. From the perspective of a socially functional denial (and an endocolonized state), to do otherwise could in and of itself be considered traumatic. As for what was alluded to with Marx's comment on "the (re)production of the social relations within which it occurs," the it is the kernel (of the socio-symbolic) that Mr. D's organization will pursue while unraveling a particular community's/society's connections (rather than disrupt the smooth flow of colonization) and interdependencies and attempting to extrapolate its findings to a larger audience.

Somewhere midpoint, Mr. D and I lost sight of the consultation and we too found ourselves lost in the hyper-colonial. We put together our case notes and a summary of the process, but it was aside from the point of our engagement. We asked ourselves: Were we analyzing the hyper-colonial as a dark element to be flushed out of hiding and labeled as toxic? Or were we attempting to master it and send it off to do our bidding? How often do we find ourselves inadvertently undertaking the Frankensteinian task of forging - or forcing - together various and disparate parts of this and that, only to find that the monstrosity ("Everything is a machine," [1]) we have birthed has assumed a life of its own, sprouted wings, and taken flight?

With our flight into the hyper-colonial, colonialism has gone underground and now resides in the consumer's fertile imagination where it performs powerful work that perpetuates colonialism in different guises [2]. Mr. D and I agree that marketing to/in a consumer culture is facilitated by a process that works because we are completely enmeshed with an advertised/consumerized milieu that invites us to "freely" create ourselves (anew) in accordance with the way in which it has already created us [15]. The hyper-colonial evolution is evident across numerous societies that are inundated with so many choices that the essence of what we need to simply get through the day has become distorted. We have observed that people are motivated toward need attainment, and as they become insatiable, they negate the ubiquitous messages (think of the warnings on cigarette packages) that speak of hazards to health or economics. These motivations speak to consumers who are hard to please, get bored easily, and become restless or discontent unless a product provides ongoing enjoyment-jouissance-that fuels a need to consume more and to simultaneously get better (i.e., more intense) effects. The walls of hyper- colonialism are splattered with a subconscious graffiti that blast signals into our unconscious minds, suggesting that ours is a society (world) that forces us to endure our mundane lives with a scarcity of resources while simultaneously offering an abundance of distractions (products, etc.) which will serve us (while milking and sustainingrather than meeting — our actual needs/ desires). Mr. D is investigating the origin and proliferation of this notion, as seen in the advertising campaign for BMW's 6 series: "U.O.U."- -you can be driven to maniacally indulge and ultimately possess a (perpetual and perpetuating) sense of (ever-shifting) satisfaction, and yet you remain psychically indebted to our Products/Objects (complete with the intergenerational transmission of the psychic interest that is accruing)...ad infinitum.

\section{REFERENCES}

[1] G. Deleuze and F. Guattari, "Anti-Oedipus: Capitalism and Schizophrenia (Vol. 1)," University of Minnesota Press, Minneapolis, 1983.

[2] S. K. Bonsu, "Colonial Images in Global Times: Consumer Interpretations of Africa and Africans in Advertising," Consumption Markets \& Culture, Vol. 12, No. 1, 
2009 , pp. 1-25.

[3] D. T. Cook, "The Missing Child in Consumption Theory," Journal of Consumer Culture, Vol. 8, No. 2, 2008, pp. 219-243.

[4] M. Tyler, "Growing Customers," Journal of Consumer Culture, Vol. 9, No. 1, 2009, pp. 55-77.

[5] D. Blackwell, "Colonialism and Globalization: A Group-Analytic Perspective," Group Analysis, Vol. 36, No. 4, 2003, pp. 445-464.

[6] A. Hearn, "Meat, Mask, Burden," Journal of Consumer Culture, Vol. 8, No. 2, 2008, pp. 197-217.

[7] R. Goldman, "Reading Ads Socially," Routeledge, New York, 1992.

[8] P. Senge and O. Scharmer, "Community Action Research: Learning as a Community of Practitioners, Consultants and Researchers," In: P. Reason and H. Bradbury, Eds, Handbook of Action Research, London, Sage, 2002, pp. 238-249.

[9] A. Money, "Material Culture and the Living Room: The Appropriation and Use of Good in Every Day Life," Journal of Consumer Culture, Vol. 7, No. 3, 2007, pp. 355-377.

[10] A. Lieblich, R. Tuval-Mashiach and T. Zilber, "Narrative research," Sage, London, 1998.

[11] M. B. Borg, Jr., "A Zombie Storms the Meathouse: Approximating Living and Undergoing Psychoanalysis in a Palliative Care Culture," Psychoanalysis, Culture and Society, Vol. 9, 2005, pp. 212-233.

[12] T. Falola, "The Dark Webs: Perspectives on Colonialism in Africa," Carolina Academy Press, Durham, 2002.

[13] E. Said, "Orientalism," Pantheon, New York, 1978.

[14] J. A. Sandlin, "Deviance, Dissonance, and Detournement," Journal of Consumer Culture, Vol. 9, No. 1, 2009, pp. 79-115.

[15] J. Williamson, "Decoding Advertisements: Ideology and Meaning in Advertising," Marion Boyars Publishing, New York, 2002.

[16] N. Ellin, "Postmodern Urbanism," Princeton Architectural Press, New York, 1996.

[17] L. Tye, "The Father of Spin," Holt, New York, 2002.

[18] A. Charles, "Colonial Discourse since Christopher Columbus," Journal of Black Studies, Vol. 26, No. 2, 1995, pp. 134-152.

[19] M. Foucault, "Discipline and Punish: The Birth of the Prison," Penguin, Harmondsworth, 1980.

[20] M. Recalcatti, "Madness and Structure in Lacan," Lacanian Ink, Vol. 32, 2008, pp. 96-121.

[21] S. Zizek, "Violence," Picador, New York, 2008.

[22] S. R. Steinberg and J. L. Kincheloe, "Kinderculture: The Corporate Construction of Childhood," Westview Press, Boulder, 1998.

[23] W. T. Ngugi, "Decolonizing the Mind: The Politics of Language in African Literature," Heinemann, Portsmouth, 1986.
[24] C. Johnson, "The Sorrows of Empire: Militarism, Secrecy, and the End of the Republic," Metropolitan Books, New York, 2004.

[25] D. Kellner, "Television and the Crisis of Democracy," Westview Press, Boulder, 1990.

[26] A. W. Schultheis, "Regenerative Fictions: Postcolonialism, Psychoanalysis, and the Nation as Family," Palgrave Macmillan, New York, 2004.

[27] R. Kahn and D. Kellner, "Resisting Globalization," In: G. Ritzer, Ed., The Blackwell Companion to Globalization, Wiley-Blackwell, London, 2007, pp. 662-674.

[28] B. Gunter and A. Furnham, "Children as Consumers: A Psychological Analysis of the Young People's Market," Routledge, London, 1998.

[29] J. Butler, "The Psychic Life of Power: Theories in Subjection," Stanford University Press, Stanford, 1997.

[30] G. Deleuze and F. Guattari, "A Thousand Plateaus: Capitalism and Schizophrenia (Vol. 2)," University of Minnesota Press, Minneapolis, 1987.

[31] H. A. Giroux, "The Abandoned Generation: Democracy Beyond the Culture of Fear," Palgrave Macmillan, New York, 2003.

[32] H. A. Giroux, "Stealing Innocence: Corporate Culture's War on Children," Palgrave, New York, 2000.

[33] J.-L. Nancy, "Self from Absence to Self," Lacanian Ink, Vol. 33, 2009, pp. 146-155.

[34] S. Zizek, "Organs without Bodies," Routledge, New York, 2004.

[35] K. Marx, "Capital, Vol. 1," Penguin, Harmondsworth, 1990.

[36] S. Zizek, "The Parallax View," The MIT Press, Cambridge, 2006.

[37] S. Homer, "Jacques Lacan," London, Routledge, 2005.

[38] S. Freud, "Taboo of virginity," Standard Edition, Vol. 11, 1917, pp. 191-208.

[39] V. Volkan, "The Need to Have Enemies and Allies," Jason Aronson, Northvale, 1988.

[40] V. Volkan, "Large-Group Identity: 'Us vs. them' Polarizations in the International Arena," Psychoanalysis, Culture \& Society, Vol. 14, No. 1, 2009, pp. 4-15.

[41] F. Dalal, "The Paradox of Belonging," Psychoanalysis, Culture \& Society, Vol. 12, No. 1, 2009, pp. 74-81.

[42] R. Mayer, "Artificial Africas: Colonial Images in the Times of Globalization," University Press of New England, Hanover, 2002.

[43] S. Clarke, "Social Theory, Psychoanalysis and Racism," Palgrave Macmillan, New York, 2004.

[44] J. Lacan, "The Seminar of Jacques Lacan, Book VII: The Ethics of Psychoanalysis 1959-1960," Routledge, London, 1992.

[45] P. Virilio and S. Lotringer, "Pure War," Semiotext(e), New York, 1997.

[46] U. Krautwurst, “Cyborg Anthropology and/as Endocolo- 
nization," Culture, Theory \& Critique, Vol. 48, No. 2, 2007, pp. 139-160.

[47] E. Levenson, "The Enigma of the Transference," Contemporary Psychoanalysis, Vol. 45, No. 1, 2009, pp. 163178.

[48] P. L. Wachtel, "Knowing Oneself from the inside out, Knowing Oneself from the outside in: The 'Inner' and 'Outer' Worlds and Their Link through Action," Psychoanalytic Psychology, Vol. 26, No. 2, 2009, pp. 158-170.

[49] S. Goldklank, "My Family Made me Do it: The Influence of Family Therapist's Origin on Their Occupational Choice," Family Process, Vol. 25, No. 3, 1986, pp. 309319.

[50] M. B. Borg, Jr., "Venturing beyond the Consulting Room:
Psychoanalysis in Community Crisis Intervention," Contemporary Psychoanalysis, Vol. 40, 2004, pp. 147-174.

[51] M. B. Borg, Jr., "Community Psychoanalysis: Developing a Model of Psychoanalytically-Informed Community Crisis Intervention," In: N. Lange and M. Wagner, Eds., Community Psychology: New Directions, Nova Science Publishers, Happague, 2010, pp. 1-66.

[52] M. B. Borg, Jr., E. Garrod, M. R. Dalla and J. McCarroll, "Can Psychoanalysis Exist outside the Consulting Room? In: B. Willock, R. Curtis and L. Bohm, Eds., Taboo or not Taboo: Forbidden Thoughts, Forbidden Acts in Psychoanalysis, International Universities Press, Madison, 2009, pp. 193-207. 